\title{
Deploying Regional Jets to Add New Spokes to a Hub
}

by

\author{
Ian Savage* and Burgess Scott ${ }^{\ddagger}$ \\ Northwestern University \\ Correspondence Address \\ Professor Ian Savage \\ Department of Economics \\ Northwestern University \\ 2001 Sheridan Road \\ Evanston, Illinois 60208 \\ Ph: (847) 491-8241 \\ Fax: (847) 491-7001 \\ E-mail: ipsavage@northwestern.edu
}

Published in Journal of Air Transport Management Volume 10(2), pages 147-150, 2004

\begin{abstract}
A common use of regional jets has been to add new spokes to existing hubs. This paper estimates a model to explain the 36 new links that were added by Delta Air Lines affiliate Comair to its Cincinnati / Northern Kentucky Airport hub between 1996 and 2001. Distance, population of the spoke city, and number of flights offered through alternative hubs were strong predictors of new service. The coefficients of the model were validated by using them to predict new links added over the same period at Atlanta, Georgia. The majority of these new routes were operated by regional jets owned by another Delta affiliate, Atlantic Southeast Airlines.
\end{abstract}

Keywords: regional jets - new service - United States

* Corresponding author

‡ Now with Lehman Brothers 


\section{Introduction}

A significant development in United States domestic aviation in the past few years has been the deployment of regional jet aircraft, which seat between 30 and 100 passengers. From the mid-1990s to the start of 2003, more than 1,100 regional jets were introduced, primarily by the regional affiliates of the mainline airlines. This sector of the industry has remained strong, despite the troubles confronting larger airlines since 2001. The General Accounting Office (2001) estimated that $41 \%$ of the route deployments by regional jets were to initiate new service (the remainder represented replacing or supplementing service previously provided by turboprops or mainline jets). Many commentators initially believed that the new routes operated by regional jets would "overfly" congested hubs and provide point-to-point service in smaller markets. In fact, our analysis of Bureau of Transportation Statistics (BTS) data found that only 3\% of regional jet routes could be clarified as such. The vast majority of the new service initiated with regional jets has been to expand service from hubs to cities that were not previously served.

This paper investigates the factors that predict which new spokes will be added to a hub when regional jets are deployed. The model is estimated using data from one of the earliest and largest deployments by Delta Air Lines affiliate Comair at its Cincinnati / Northern Kentucky Airport hub. The parameters of the model are then validated by applying them to routes from Atlanta Hartsfield International Airport, Georgia, where another Delta affiliate, Atlantic Southeast Airlines, is the dominant operator of regional jets.

\section{The Cincinnati Market}

Delta had established a hub in Cincinnati after deregulation, and the hub expanded rapidly. The expansion was probably not motivated by growth of the Cincinnati market. While Greater Cincinnati has a rich industrial base, it has now slipped out of the top 20 U.S. metropolitan areas in terms of population. A more likely reason was to provide competition to nearby hubs that funnel traffic between the Northeast and the Midwest. Its principal competitors are Continental in Cleveland, US Airways in Pittsburgh, Northwest in Detroit, America West in Columbus, American (former TWA) in St. Louis, and United and American in Chicago.

The analysis compares nonstop service to and from Cincinnati in August 1996 and August 2001. The dates were selected to represent a period before the mass introduction of regional jet service, and a period that is sandwiched between a strike at Comair in the spring of 2001 and the terrorist attacks of September 11, 2001. There are 198 United States commercial airports within 1,000 air miles of Cincinnati which can accommodate at least a turboprop aircraft. This distance was selected as representing the upper bound for normal commercial deployment of regional jets (Dresner, Windle and Zhou, 2002). Because the data for the analysis comes from United States government sources, airports in Canada are excluded. In August 1996, there was nonstop service to 57 of these airports by a combination of Comair, Delta and other airlines. By August 2001, service was initiated to 36 of the 141 cities that were unserved in 1996 . All of the new service was provided by Comair, and all but two of new services were exclusively using regional jets. (Manchester, New Hampshire had service partly provided by Comair regional jets and partly by Delta using mainline jets, and Burlington, Vermont was serviced by Comair turboprops.) The

remaining 105 airports still did not have any nonstop service. The data used for the regression is 
for the 141 unserved airports in 1996, and the models attempt to explain the choice of the 36 routes that Comair entered over the following five years.

\section{Models and Data}

Two reduced form equations are estimated. Both models have the same explanatory variables, but differ in their dependent variable. The first equation has a binary (0-1) dependent variable indicating whether Comair initiated nonstop service or not by August 2001. This equation is estimated using a probit regression. The second equation analyzes the frequency of service. The dependent variable is the number of monthly nonstop flights to the spoke city in August 2001, obtained from the BTS on-line domestic segment database. If nonstop service was not provided, this variable was set equal to zero. This equation was estimated by ordinary least squares. While the dependent variable can only take non-negative integer values, a negative binomial regression was rejected as flight frequency is not regarded as generated by a Poisson process.

Six exogenous variables were used to look at the attractiveness of a potential spoke. The first is the air distance. The second is the 2000 Census population of the Metropolitan Statistical Area (MSA) or Primary Metropolitan Statistical Area (PMSA) at the end of the spoke. The third measures the underlying demand between the spoke airport and Cincinnati. The BTS T-100 domestic market database was used to obtain the average number of inbound and outbound passengers purchasing tickets with the spoke airport and Cincinnati as the origin and destination in calendar year 1996 regardless of carrier or routing (of course, such a trip would require a connection in 1996). This was expressed as a rate per capita, by dividing by the population of the spoke city, and will be a proxy for those cities where there are substantial personal or business ties with Cincinnati. Population and underlying origin-destination traffic should be positive predictors of new service, whereas the effect of distance is less certain.

The final three measures look at the relative desirability of alternative methods of traveling in 1996. For each spoke airport, the most logical connecting airport was selected on the basis that it was an established hub that was in the general direction of Cincinnati, had nonstop service to Cincinnati, and provided the most number of flights to the spoke airport. Variables four and five were used to measure the desirability of this connection. The fourth variable was the ratio of the air distance from the spoke to Cincinnati via the connecting city versus the direct air distance. The more circuitous the routing, the more likely that nonstop service would be initiated. The fifth variable measured the ease of the connection and was the number of monthly flights by any airline in August 1996 from the spoke airport to the connecting airport. Very frequent and convenient connecting flights should prove to be a disincentive to entry. The final variable was a dummy variable indicating whether the spoke city was within 60 air miles of a city that already had nonstop service to Cincinnati in 1996. Presumably, passengers from Cincinnati would fly to this city and then drive, and this would prove to be a disincentive to initiating direct service.

A possible concern was that some of these explanatory variables would be highly collinear. This turned out not to be the case. The highest collinearity was -0.502 between the ratio of the connection distance to the direct air distance, and the length of the spoke. This negative relationship is to be expected, as it is logical that the possibility of a very circuitous routing through 
a connecting city will decrease as the spoke length increases. There was also a positive correlation of 0.456 between spoke city population and the proximity to an airport that already had nonstop service to Cincinnati in 1996, probably due to the high density of population centers along the East Coast. The correlation between other explanatory variables was very low.

\section{Results for Cincinnati}

The results of the regressions are shown in Table 1 . The results for the probit model are from the "dprobit" option in STATA. Rather than reporting coefficients, the results are the change in the predicted probability for an infinitesimal change in each independent continuous variable, and for a discrete change in the probability for the dummy variable. The goodness of fit was about 0.25 (measured as the $\mathrm{R}^{2}$ in the linear model and the pseudo- $\mathrm{R}^{2}$ in the probit model).

The probability of entry, and the frequency of any service that is established, declines significantly as the distance from Cincinnati approaches 1,000 miles. This suggests that the most prevalent markets for regional jets are shorter routes. An alternative functional form incorporating distance squared, to permit the possibility of an inverted U-shaped relationship between entry and distance, was tried but was found to produce a worse fit to the data. Not surprisingly, the larger the population of the spoke city, the more likely it was to receive service and to receive a higher frequency of service. The underlying per capita demand for travel between the spoke city and Cincinnati in 1996 was not found to affect the probability that new service was initiated, but it was significantly positively related to the frequency of new service.

Using the linear model of flight frequency, sample elasticities were estimated at mean values. A $10 \%$ increase in distance is predicted to reduce flight frequencies by $21 \%$. A $10 \%$ increase in spoke population increases frequency by $4 \%$, and a $10 \%$ increase in the per capita underlying demand between the spoke city and Cincinnati increases frequency by $0.4 \%$. The effect of the latter variable is, in practice, quite small suggesting that the new services were aimed at attracting passengers to use Cincinnati as a hub rather than primarily serving passengers whose origin or destination is Cincinnati.

The degree of which the alternative routing requires flying additional distance, and the proximity to another airport that already had nonstop service in 1996 was not found to be statistically related to new entry or flight frequency. However, the number of flights to the best connecting hub in 1996 was found to be highly positively related to entry and flight frequency. This result is counterintuitive, if it is argued that frequent existing connections should decrease the attractiveness of entry. In practice, the opposite is true. It would appear that this variable is probably a proxy for the amount of traffic that a spoke airport generates and attracts. Most of these passengers are making connecting flights to and from destinations other than Cincinnati. A large market would make it attractive for Comair to enter and offer Cincinnati as an alternative hub.

\section{Model Validation}

The probit model was validated by application to Atlanta Hartsfield International Airport. This was the location of another large and early deployment of regional jets by another Delta 
affiliate, Atlantic Southeast Airlines. Using similar definitions as those for Cincinnati, it was found that there are 192 commercial airports within 1,000 air miles of Atlanta. In August 1996, there was nonstop service to 101 of these airports. This is a much higher proportion than in Cincinnati reflecting the fact that while Cincinnati is an "up and coming" hub, Atlanta is an established hub and is the home base for both Delta and Atlantic Southeast. For the 91 airports that did not have nonstop service, data was collected on the six explanatory variables in an identical manner to the earlier analysis of Cincinnati. The estimated probit regression for Cincinnati was used with the Atlanta data to predict the probability that service would be initiated by August 2001. The regression predictions for the 91 unserved airports in 1996, ranged from a probability of close to one for Alexandria, Louisiana down to 0.0055 for Portsmouth, New Hampshire (the full set of predictions is available from the authors).

In August 2001, entry had taken place on 16 out of the 91 routes. Ten of the 16 service initiations were by Atlantic Southeast Airlines using regional jets. One was by Atlantic Southeast using a 30-seat turboprop. Another four were by low-cost carrier Airtran Airways using small 106-seat DC9 conventional jets. Airtran has much in common with the regional jet operators in that it uses smaller aircraft, and has a relatively low cost structure. The final new service was initiated by Delta using MD80 aircraft on the long 952-mile route to Manchester, New Hampshire.

Overall, 11 of the 16 routes that received new service between 1996 and 2001 were among the top 25 routes predicted by the model. That said, three of the top five predicted airports did not receive service. On closer examination, both Alexandria, Louisiana and Lafayette, Louisiana (ranked 1 and 2) are both within a one hour drive of one of four airports that already had service to Atlanta in 1996, and St. Petersburg, Florida (ranked 4) is only 17 miles from Tampa which has extensive service to Atlanta. The three low ranked airports that received service (Worcester, Massachusetts at number 63, Manchester, New Hampshire at 71 and White Plains, New York at 76) have a common characteristic. They are all long routes of more than 800 miles that serve the outer suburbs and are alternatives to congested big city airports in Boston (in the case of Worcester and Manchester) and New York City (in the case of White Plains). It is clear that our model does not sufficiently quantify this effect.

\section{Conclusions}

Despite the predictions of some commentators that regional jets would be used to overfly congested hubs and provide point-to-point service, the reverse seems to be true. Regional jets have been used to build up existing hubs. In Atlanta they have been used to add spokes to an already mature hub. In Cincinnati they have been used in an aggressive attempt to build up Delta's hub at the expense of rival hubs that funnel traffic between smaller cities in the Northeast and the Midwest of the United States. This paper estimates that the attractiveness of regional jet deployment declines with route length, but is positively related to the population of the spoke city, the number of passengers whose origin and destination are the hub and the spoke city, and the number of flights from the spoke to an alternative hub. 


\section{$\underline{\text { References }}$}

Dresner, M., R Windle and M. Zhou, 2002. Regional jet services: Supply and demand. Journal of Air Transport Management 8(5), 267-273.

General Accounting Office, 2001. Aviation Competition: Regional Jet Service Yet to Reach Many Small Communities. GAO-01-344. U.S. Government Printing Office, Washington DC.

United States Bureau of the Census, 2001. Census 2000. U.S. Government Printing Office, Washington DC.

United States Bureau of Transportation Statistics, various years. Air Carrier Statistics. U.S. Government Printing Office, Washington DC. <http://www.transtats.bts.gov> 
TABLE 1: Regression Results for Cincinnati

\begin{tabular}{|c|c|c|}
\hline Dependent variable & Entry by August 2001 & $\begin{array}{l}\text { Monthly One-way Flights } \\
\text { in August } 2001\end{array}$ \\
\hline Regression Format & Probit & OLS \\
\hline \multicolumn{3}{|c|}{$\begin{array}{l}\text { Independent variables ( } \mathrm{t} \text { statistics in parentheses). See text for interpreting the reporting of } \\
\text { results for the probit model. }\end{array}$} \\
\hline Constant & - & $\begin{array}{c}27.455 \\
(1.41)\end{array}$ \\
\hline Air Distance from Cincinnati & $\begin{array}{c}-0.0008 \\
(3.13)\end{array}$ & $\begin{array}{c}-0.0069 \\
(3.80)\end{array}$ \\
\hline Population & $\begin{array}{l}2.9 \times 10^{-7} \\
(2.52)\end{array}$ & $\begin{array}{l}2.7 \times 10^{-5} \\
(2.81)\end{array}$ \\
\hline $\begin{array}{l}\text { Per capita demand to/from } \\
\text { Cincinnati in } 1996\end{array}$ & $\begin{array}{l}30.273 \\
(1.08)\end{array}$ & $\begin{array}{c}265.851 \\
(2.12)\end{array}$ \\
\hline $\begin{array}{l}\text { Ratio of air distance through best } \\
\text { connecting airport to direct air } \\
\text { distance }\end{array}$ & $\begin{array}{r}-0.039 \\
(0.43)\end{array}$ & $\begin{array}{l}1.646 \\
(0.24)\end{array}$ \\
\hline $\begin{array}{l}\text { Number of flights to best } \\
\text { connecting airport in August } 1996\end{array}$ & $\begin{array}{c}0.0014 \\
(2.94)\end{array}$ & $\begin{array}{l}0.117 \\
(3.32)\end{array}$ \\
\hline $\begin{array}{l}\text { Dummy variable = } 1 \text { if within } 60 \\
\text { miles of airport with nonstop } \\
\text { service to Cincinnati in August } \\
1996\end{array}$ & $\begin{array}{l}0.079 \\
(0.68)\end{array}$ & $\begin{array}{l}-7.862 \\
(0.828)\end{array}$ \\
\hline Number of observations & 141 & 141 \\
\hline Log Likelihood & -60.72 & - \\
\hline Pseudo $\mathrm{R}^{2}$ & 0.242 & - \\
\hline $\mathrm{R}^{2}$ & - & 0.263 \\
\hline
\end{tabular}

